\title{
Outcome of head injury patients admitted as unknown: A retrospective study
}

\author{
Anuj Kumar Tripathi ${ }^{1 *}$, Raj Awasthi ${ }^{2}$ \\ ${ }^{1,2}$ Assistant Professor, Dept. of General Surgery, Career Institute of Medical Sciences and Hospital, Lucknow, Uttar Pradesh, India
}

*Corresponding Author: Anuj Kumar Tripathi

Email: dranujkumartripathi@gmail.com

\begin{abstract}
"Unknown" head injury patients are a major burden for our country. Government has provided road side aid for such victims throughout the country. A retrospective analysis was done on 52 head injury patients admitted in the department of Neurosurgery as 'unknown' closed head injury cases between September $30^{\text {th }} 2018$ to $31^{\text {st }}$ December 2019. The paper also emphasises on the treatment aspect of such patients.
\end{abstract}

Keywords: Unknown, Head injury, Highway.

\section{Introduction}

Road traffic accidents are one of the causes of debility, wound and mortality. India has the utmost road traffic accident rate worldwide with over 140000 deaths annually. Hence road accident is 'a global tragedy' with ascending trend. "Unknown" head injury patients are a major burden for highway based hospital. Unknown patients are someone who are not identified at admission. The term "unknown" means when the head injury patient and gets admitted through someone other than their own relative for the treatment. Career institute of medical sciences and hospital, I.I.M Road, Ghailla, Lucknow, Uattar Pradesh. situated on link road of Hardoi and Sitapur highway. It has a quite high trauma load per day. Most of the cases are of villagers, who are brought by police and other people. A survey according to the Times of India on $19^{\text {th }}$ November, 2019 road traffic accident (RTA) patterns ${ }^{1}$ shown in Fig. 1.

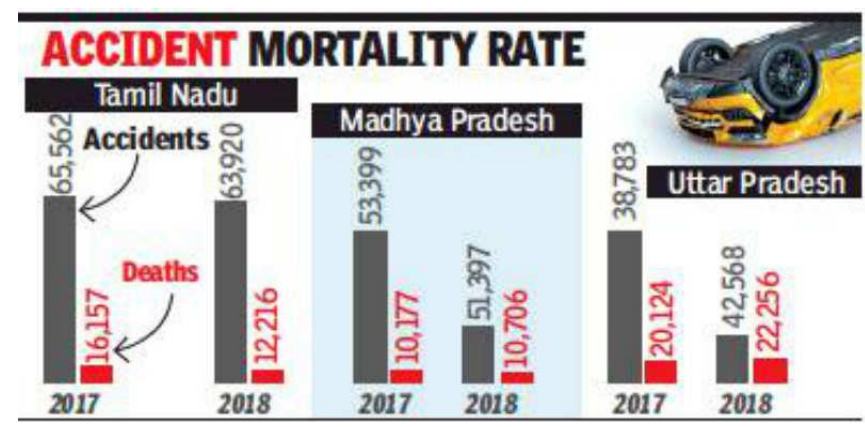

Fig. 1

\section{Materials and Methods}

A retrospective analysis was done from $30^{\text {th }}$ September, 2018 to $31^{\text {st }}$ December, 2019. During the study period, 52 head injury patients were admitted to the department of Neurosurgery as 'unknown'. Conscious head injury patients who could identify themselves or serious head injury patients who were accompanied by somebody known to them or could be identified within $24 \mathrm{hr}$ were excluded from the study group. None of the patient were deprived of any medicine, Intensive Care Unit (ICU) care, computerized tomography (CT) scan, nutritious food or surgery.

\section{Result}

Table 1: Demographic profile

\begin{tabular}{|l|c|c|}
\hline S. No. & Age group(years) & Number of cases \\
\hline 1 & $10-20$ & 2 \\
\hline 2 & $20-30$ & 17 \\
\hline 3 & $30-40$ & 13 \\
\hline 4 & $40-50$ & 9 \\
\hline 5 & Above 50 & 11 \\
\hline
\end{tabular}

Table 2: Severity of head injury

\begin{tabular}{|l|c|}
\hline Glasgow coma scale score & Number of cases \\
\hline $13-15$ & 29 \\
\hline $9-12$ & 10 \\
\hline 8 or less than 8 & 13 \\
\hline
\end{tabular}

In the study male to female ratio was $8: 1$. Out of 52 patients, $19(36.5 \%)$ cases were operated for head injury and mortality rate was seen in $7(36.8 \%)$ cases. Out of 52 cases, 37 (82.2) cases were identified and sent home. Eight cases $(17.7 \%)$ remained unknown and were sent to rehabilitation/poor homes with the help of medical social worker.

\section{Discussion}

In all unknown cases of head injury medico legal formalities were performed. None of the patient was deprived of any medicine, ICU care, CT scan, nutritious food or surgery because of hospital policy (as decided by our Hon'ble 
Chairman Dr Azmat Ali and trustee members). In traumatic brain injury cases patient is most of time disoriented and are unable to remember events, unable to state their name and address. ${ }^{2,3}$ An altered behavioural pattern are of special importance in the context of unknown patients. They stay in the hospital for longer periods than required. Unknown patients represent a unique subgroup in metropolitan cities and managing those raises several issues such as duration of their stay, management of their diet, search of their address and their relatives. The relocation of such patient to their appropriate address is vital and complicated due to their unwell mental status. Many of them occupy hospital beds for longer duration than required. This also causes undue economic burden on the hospital. In India, there is an acute shortage of rehabilitation homes ${ }^{4}$ comparison to other developed countries. During their hospital stay, right from the time of admission till the time of discharge or death of these patients, difficulties abound. These problems range from obtaining the consent for surgery and providing free of cost drugs, treatment, food, and nutrition. These patients can succumb to secondary insults, in case proper nursing care is not provided.

Trained manpower is required to deliver them with basic care. It is imperious to reinforce our healthcare delivery systems in peripheral hospitals as this will help in preventing needless delay in commencement of the treatment for such unknown patients.

\section{Conclusion}

This particular subgroup of patients represents distinctive challenges in their management. The purpose of this study was to create an awareness regarding these difficulties at trauma centre in a developing country like India.

\section{Source of Funding}

None.

\section{Conflict of Interest}

None.

\section{References}

1. https://timesofindia.indiatimes.com/2019/11/19/archivelist/yea r-2019,month-11, starttime-43788.cms

2. de Guise E, Feyz M, LeBlanc J, Richard SL, Lamoureux J. Overview of traumatic brain injury patients at a tertiary trauma centre. Can J Neurol Sci. 2005;32:186-93.

3. Mathias JL, Mansfield KM. Prospective and declarative memory problems following moderate and severe traumatic brain injury. Brain Inj. 2005;19:271-82.

4. Ahmad FU, Mahapatra AK, Mehta VS. Outcome of "unknown" head injury patients at a tertiary care neurosurgical centre. Neurol India. 2006;54:73-4.

How to cite this article: Tripathi AK, Awasthi R. Outcome of head injury patients admitted as unknown: A retrospective study. IP Indian J Anat Surg Head Neck Brain. 2020;6(1):14-5. 